\title{
Framework for Operational Performance Measurements in Small and Medium Scale Industries Using Discrete Event Simulation Approach
}

\author{
Babatunde Omoniyi Odedairo \\ Department of Industrial and Production Engineering \\ University of Ibadan \\ Ibadan, Nigeria \\ bo.odedairo@ui.edu.ng
}

\author{
Nnamdi Nwabuokie \\ Department of Industrial and Production Engineering \\ University of Ibadan \\ Ibadan, Nigeria \\ valiantnnamdi@yahoo.ca
}

\begin{abstract}
Globally, production systems must cope with limitations arising from variabilities and complexities due to globalization and technological advancements. To survive in spite of these challenges, critical process measures need to be closely monitored to ensure improved system performance. For production managers, the availability of accurate measurements which depict the status of production activities in real time is desired. This study is designed to develop an operational data decision support tool (ODATA-DST) using discrete event simulation approach. The work-in-process and processing time of each workstation/buffer station in a bottled water production system were investigated. The status of each job as they move through the system was used to simulate a routing matrix. The production output data for $50 \mathrm{cl}$ and $75 \mathrm{cl}$ product from 2014-2016 were collected. A mathematical model for routing jobs from the point of arrival to the point of departure was developed using discrete event simulation. A graphical user interface (GUI) was designed based on the factory's performance measurement algorithm. Simulating the factory's work-in-process with respect to internal benchmarks yielded a cycle time of 4.4, 6.23, 5.04 and throughput of $0.645,0.455,0.637$ for best case scenario, worst case scenario and practical worst case scenario respectively. The factory performed below the simulated benchmark at $26 \%, 28 \%$, $28 \%$ for the $50 \mathrm{cl}$ and at $51 \%, 54 \%, 59 \%$ for $75 \mathrm{cl}$ regarding the year 2014, 2015 and 2017 respectively. Performance measurement decision support tool has been developed to enhance the production manager's decision making capability. The tool can improve production data analysis and performance predictions.
\end{abstract}

Keywords-performance measures; production system; discrete event simulation;decision support system

\section{INTRODUCTION}

The need for continuous performance improvement in a production system despite the complexities arising from market fluctuations will continue to drive the desire for innovative research. Performance measurement, a sub-division of performance evaluation involves the selection of appropriate quantitative measures to aid decision making in a system. These measures are vital input into any decision support tools (DST) $[1,2]$. Also, such measures are required to assist executives at different decision levels. Ultimately, these decisions will contribute to the actualization of the strategic goals of the organization [3-7]. Authors in [8] classified performance measures into: (1) measure focus, and (2) measure tense. The former comprises of financial (monetary) and operational (non-monetary) data, while measure tense entails studying the past to improve the present. Diverse studies have been carried out on how to measure system performance using DST [6, 9-11]. This is necessary as the profitability, productivity, and survivability of any production system largely depend on the quality of the decisions obtained from such tools. DST in a production system can be deployed at operational, tactical and strategic levels. However, due to the ambiguities associated with most decision processes, the need to smoothen the complexities associated with choosing the best alternative cannot be ignored [12].

Decision support tools relevant to the production system include the following: (1) thermodynamics and exergy analysis, (2) optimization, and (3) simulation [13-16]. On simulation, the aim is to imitate real-world process over time $[17,18]$. Also, in a simulation model, discrete mathematics can be employed in which events of various kinds are kept and governed in a queue for each object [19]. Discrete event simulation (DES) considers state changes at discrete points (points which an event occurs). It can be used to answer "what if" scenarios, diagnose the occurrence of certain phenomena and enhance system development over time [12, 17, 20-22]. Despite the increase in the research work on using DES as a DST, empirical studies have shown that it is minimally used in production systems [1, 12, 23-25]. In Nigeria, one of several challenges limiting the performance of small and medium scale enterprises (SMEs) involved in production process is the lack of access to proprietary DST $[7,26,27]$. Based on this reality, in this study the objective is to develop an operational data DST (ODATADST) for a bottled water factory using DES analytical approach. The rest of this paper is structured as follows: A brief discussion on DST and DES is the focus of section II. In section III, ODATA-DST was developed using an illustrative example. Results from the example and conclusion are the focus of sections IV and V respectively. 


\section{RELATED LITERATURE}

In [18] authors suggested some performance measures peculiar to most production systems, these include, but are not limited to, the following: (1) throughput under mean and peak load resources, (2) labor and machine utilization, (3) bottlenecks and choke points, (4) staff requirements, (5) queuing and delays caused by material handling, (6) work in process and (7) scheduling effectiveness. On the need to improve efficiency of the supply chain, author in [11] designed a performance measurement system for Thai automotive industries using data categorization, clustering, and examination. Author in [10] developed a fuzzy data warehouse model to measure business performance as a result of the everincreasing complexity and heterogeneous nature of the data available to organizations. He concluded that fuzzy sets and linguistic variables have the ability to deal with imprecision, vagueness and uncertainty nature of production data for better decision making. Authors in [13] commented that the decision making process is driven by the following: (1) communication, (2) documentation, (3) knowledge and (4) model development. Models are used to demystify the complexity associated with many problems. Authors in [28, 29] identified some of the processes in modeling as: (1) data assessment and reduction, (2) state estimation, (3) monitoring, (4) diagnosis, (5) prediction, (6) hypothesis generation, (7) creation of mathematical image to a problem, and (8) decision making. Discrete event simulation (DES) model is a computer simulation method universally suitable for modeling the performance of a production system. The method can be used to abstract the dynamic and stochastic behavior of a system as a set of discrete sequence of events by considering event in instants of time [30]. Also, DES demands less computer resources and is useful in solving statistical uncertainties and discrepancies in simulated environments. On the use of DES in production systems, authors in [31] developed a simulation based real-time decision making tool for a manufacturing automation system. Authors in [32] presented the use of DES for planning, production and scheduling decisions. In [33], authors utilized DES for customer driven manufacturing system design. Author in [19] combined simulation and optimization to improve decision support in an energy efficiency industry.

\section{METHODOLOGY}

The mathematical model proposed in [34, 35] on factory's performance measurement was adopted. In Table I, the various operational performance measures required to understand the behavior of the production line are defined.

\section{A. Descriptive Problem Definition}

The flow process of a small scaled bottled water production plant is described in Figure 1. The process consists of a production line with 9 workstations (A1-A9) defined in Table II. The workstations are arranged in series with each job following the same processing sequence. In designing a discrete event simulation framework, the study of the production line will be limited to workstations A2 to A9 because their activities are discrete events. For each discrete event, there is a change in the state of the product as it moves from one workstation to another until it becomes a finished product. Each workstation (A2-A9) has at least one subworkstation. Job routing of the production system is presented in Figure 2.

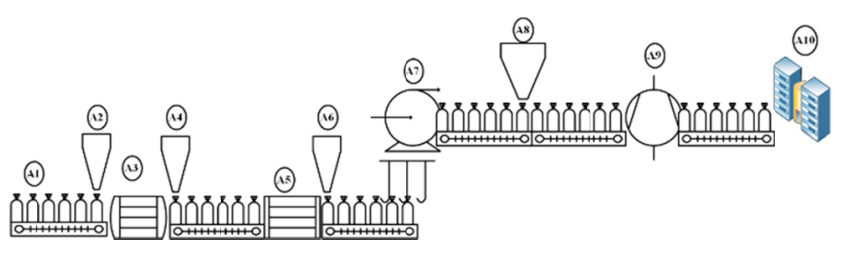

Fig. 1. Plant layout of the bottled water production plant.

\section{B. Model Assumptions}

- The bottled water factory is a serial production line with finished goods buffers.

- The cycle time of the machines is constant while the throughput time varies with respect to its state (in terms of been empty or saturated).

- Processing time in each workstation is deterministic but varies from one workstation to the other.

- Buffer capacity between successive work stations is finite.

- The production line is reliable with a steady state exponential distribution failure rate.

- Blockage of a station occurs if the jobs at the downstream buffers are beyond its capacity.

- The factory production line model has no machine downtimes, no loss in production due to waste and it is constantly in operation.

TABLE I. BASIC NOTATIONS

\begin{tabular}{|c|c|}
\hline Notation & Definition \\
\hline WIP & Work-in-process \\
\hline $\mathbf{C T}$ & Cycle time \\
\hline $\mathbf{C T}_{\text {best }}$ & Cycle time at best case performance \\
\hline $\mathbf{T}_{\text {approx }}$ & Time for a job to go through an uncongested line \\
\hline $\mathbf{C}_{\text {approx }}$ & Capacity of the line \\
\hline $\mathbf{T H}$ & Throughput \\
\hline $\mathbf{C T}_{\text {worst }}$ & Cycle time for worst case performance \\
\hline PR & Production rate \\
\hline $\mathbf{W 0}$ & Critical Work-in-process \\
\hline THbest & Maximum throughput at best-case performance scenario \\
\hline $\mathbf{N}$ & Number of stations \\
\hline $\mathbf{W}$ & Level of work-in-process \\
\hline To & Raw process time \\
\hline $\mathbf{T}$ & Average processing time \\
\hline THworst & Throughput for worst case performance scenario \\
\hline $\mathbf{r}_{\mathbf{b}}$ & Bottleneck rate \\
\hline
\end{tabular}

\section{Mathematical Model}

To model ODATA-DST using DES framework, the following measures were adopted.

- Cycle time

Case 1: When the production line is relatively empty 
$C T=T_{\text {approx }}$

Case 2: When the production line is saturated

$C T=\max \left\{T_{\text {approx. }}, \frac{\text { WIP }}{C_{\text {approx }}}\right\}$

- Machine Capacity

$C_{\text {approx. }}=\frac{1}{C T}$

- Throughput

TH $=C_{\text {approx }} * P R$

- Work-in-process (from Little’s Law)

$W I P=T H \times C T$

- Bottleneck rate

$r_{b}=\frac{1}{T}$

- Average time at a station

$W_{0}=r_{b} T_{0}$

TABLE II. PLANT NAMING CONVENTION

\begin{tabular}{|c|c|c|}
\hline Conventions & Name & Description \\
\hline A1 & Belt conveyor & Belt conveyor \\
\hline A2 & Buffer station 1 & Buffer station 1 \\
\hline A3 & Workstation 1 & Automatic rinsing machine \\
\hline A4 & Buffer station 2 & Buffer station 2 \\
\hline A5 & Workstation 2 & Automatic filling machine \\
\hline A6 & Buffer station 3 & Buffer station 3 \\
\hline A7 & Workstation 3 & Automatic capping machine \\
\hline A8 & Buffer station 4 & Buffer station 4 \\
\hline A9 & Workstation 4 & Automatic Packaging machine \\
\hline A10 & Warehouse & Warehouse \\
\hline
\end{tabular}

\section{ODATA-DST Graphic User Interface}

The computer implementation of ODATA-DST was achieved using visual basic application (VBA) integrated development environment. The following motivated the use of VBA: (1) compatibility, (2) availability across multiple platforms, (3) interactive nature, and (4) ease of numerical programming. A screenshot of ODATA is shown in Figure 3.

\section{E. Best-Case Scenario, Worst-Case Scenario and Pratical}

Worst-Case Scenario of the Production Line

Analyzing the production line based on the best-case scenario, worst-case scenario and practical worst-case scenario is essential. These parameters are required to measure performance, determine the possible behavior, and areas requiring improvement at any time period.

\section{1) Best-Case Performance (BCP)}

This can be classified into minimum cycle time and maximum throughput. Minimum cycle time for a given WIP level (w) is given by:

$$
C T_{\text {best }}=\left\{\begin{array}{l}
T_{0} \text { if } w \leq W_{-} 0 \\
\frac{w}{r_{b}} \text { otherwise }
\end{array}\right.
$$

Maximum throughput for a WIP level given by $T H_{\text {best }}$ :

$$
T H_{\text {best }}=\left\{\begin{array}{l}
\frac{w}{T_{0}} \text { if } w \leq W_{0} \\
r_{b} \text { otherwise }
\end{array}\right.
$$

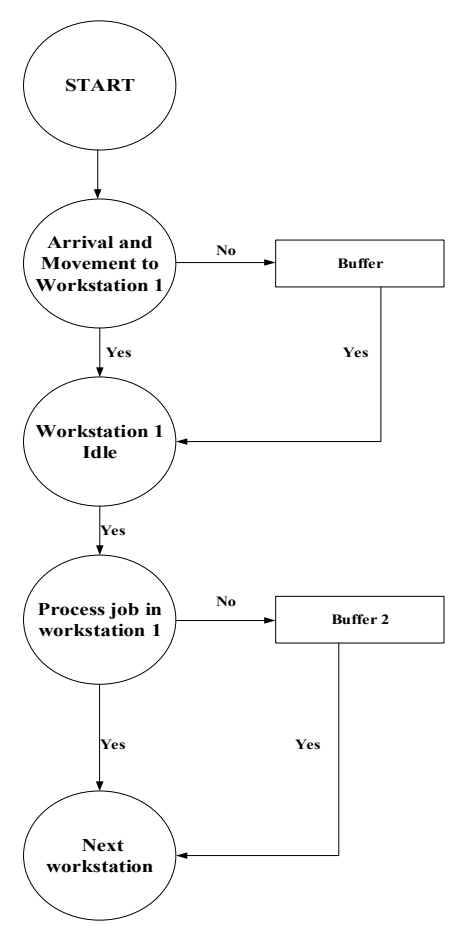

Fig. 2. Flow chart of job routing.

\section{2) Worst-Case Performance (WCP)}

This involves the maximum cycle time and minimum throughput possible for a line with bottleneck rate $r_{b}$ and raw process time $\left(T_{0}\right)$. Equation (10) is the worst-case cycle time for a given WIP level w.

$C T_{\text {worst }}=w T_{0}$

Equations (11)-(13) are the worst-case throughput for a given WIP level w.

$$
\begin{aligned}
& \text { TH } H_{\text {worst }}=\frac{1}{T_{0}} \\
& C T=N\left(1+\frac{w-1}{N}\right) t \\
& =T_{0}+\frac{w-1}{r_{b}}
\end{aligned}
$$
be:

Applying Little's law, the corresponding throughput will

$$
\begin{aligned}
& T H=\frac{W I P}{C T} \\
& =\left(\frac{w}{W_{0}+w-1}\right) r_{b}
\end{aligned}
$$

3) Practical Worst-Case (PWC)

Equation (16) is the cycle time for a PWC.

$C T_{P W C}=T_{0}+\frac{w-1}{r_{b}}$ 
The PWC throughput for a given WIP level is given by:

$$
T H_{p w c}=\left(\frac{w}{w_{0}+w-1}\right) r_{b}
$$

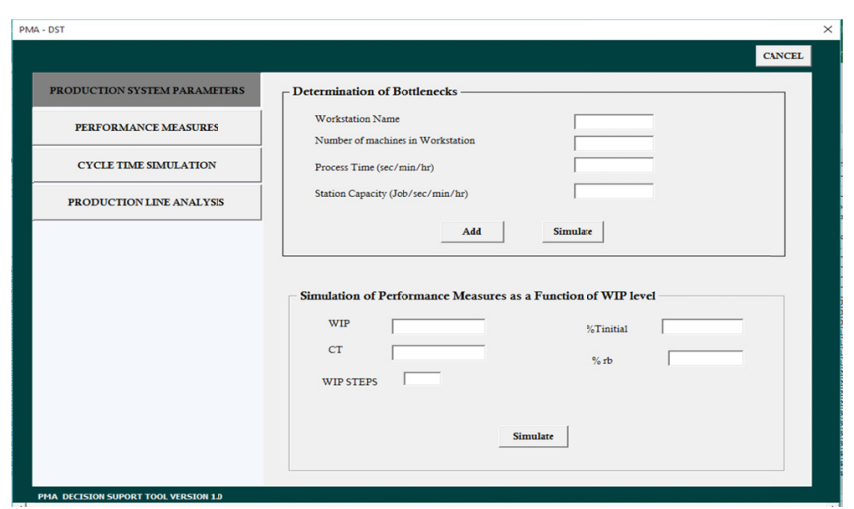

Fig. 3. ODATA - DST screen

\section{RESUlts}

The results are presented in Table III. Workstation 4 has a bottleneck of $0.645 \mathrm{jobs} /$ minute, the critical work-in-process required to achieve maximum throughput at raw processing time of 2.2 minutes is 1.419 cartons. The raw process time was 2.2 minutes. This is lower than the sum of each workstation process time, as proposed in [34]. The relationship between the best-case, worst-case and practical worst case scenarios in relation to cycle time and throughput is presented in Table IV. For $50 \mathrm{cl}$ bottled water production, minimum and maximum output were $16 \%$ and $40 \%$ and occurred in March and November respectively. For the $75 \mathrm{cl}$, minimum and maximum outputs were $28 \%$ and $83 \%$ in July and May respectively. The relationships between work-in-process and throughput for $50 \mathrm{cl}$ and $75 \mathrm{cl}$ are shown in Figures 4 and 5 respectively.

\section{CONCLUSIONS}

A performance measurement support tool has been developed to enhance production manager's decision making capability. Performance measures like cycle time, throughput, machine capacity, work-in-process, bottleneck rate and raw process time were used to derive a suitable benchmark. The tool is capable of improving production data analysis and performance predictions.

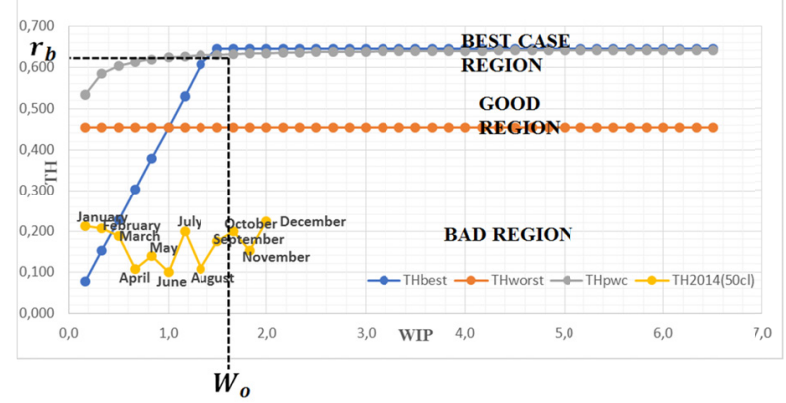

Fig. 4. Relationship between throughput and work in process (50cl bottle)

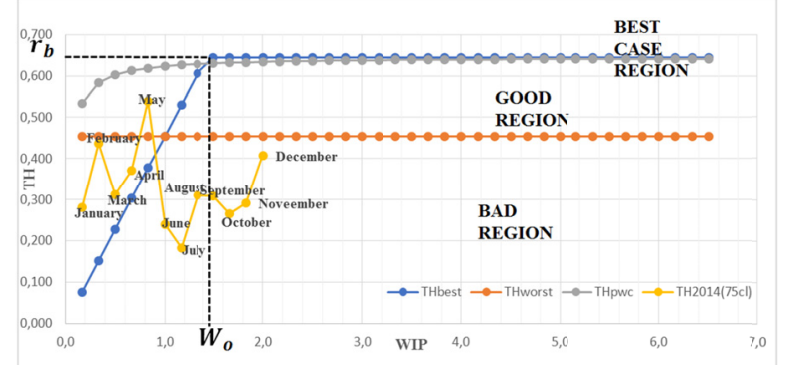

Fig. 5. Relationship between throughput and work in process $(75 \mathrm{cl}$ bottle)

TABLE III. RESULTS FROM ODATA-DST

\begin{tabular}{|c|c|c|c|c|c|}
\hline Station Number & Number of Machines & Process Times (secs) & Process Times (mins) & Jobs/Minute & Station Capacity (Job/sec) \\
\hline Buffer 1 & 4 & 3 & 0.050 & 80 & 1.3333 \\
\hline WorkStation 1 & 4 & 8 & 0.133 & 30 & 0.5000 \\
\hline Buffer 2 & 4 & 4 & 0.067 & 60 & 1.0000 \\
\hline WorkStation 2 & 4 & 8 & 0.133 & 30 & 0.5000 \\
\hline Buffer 3 & 4 & 5 & 0.083 & 48 & 0.8000 \\
\hline WorkStation 3 & 3 & 3 & 0.050 & 60 & 1.0000 \\
\hline Buffer 4 & 4 & 21 & 0.350 & 11.428 & 0.1905 \\
\hline Work Station 4 & 1 & 93 & 1.550 & 0.645 & 0.0108 \\
\hline \multicolumn{2}{|c|}{ Average Processing time } & 18.125 & Raw Process time & 2.20 \\
\hline \multicolumn{2}{|c|}{ Bottleneck } & 0.645 & \multicolumn{2}{c|}{ Critical WIP } & 1.419 \\
\hline
\end{tabular}

TABLE IV. INTERNAL BENCHMARK OUTPUT

\begin{tabular}{|c|c|c|c|c|c|c|c|}
\hline \multirow{2}{*}{ W (Bottles) } & \multirow{2}{*}{ W (Cartons) } & \multicolumn{2}{|c|}{ Best Case Scenario } & \multicolumn{2}{c|}{ Worst Case Scenario } & \multicolumn{2}{c|}{ Practical Worst Case Scenario } \\
\cline { 3 - 8 } & & CTbest (mins) & THbest (mins) & CTworst (mins) & THworst (mins) & CTpwc (mins) & THpwc (mins) \\
\hline 10 & 0.8 & 2.2 & 0.379 & 1.83 & 0.455 & 1.94 & 0.619 \\
\hline 20 & 1.7 & 2.6 & 0.645 & 3.67 & 0.455 & 3.23 & 0.632 \\
\hline 30 & 2.5 & 3.9 & 0.645 & 5.50 & 0.455 & 4.53 & 0.636 \\
\hline 40 & 3.3 & 5.2 & 0.645 & 7.33 & 0.455 & 5.82 & 0.638 \\
\hline 60 & 5.0 & 7.8 & 0.645 & 11.00 & 0.455 & 8.40 & 0.641 \\
\hline 70 & 5.8 & 9.0 & 0.645 & 12.83 & 0.455 & 9.69 & 0.641 \\
\hline
\end{tabular}




\section{REFERENCES}

[1] J. Heilala, J. Montonen, P. Jarvinen, S. Kivikunnas, "Decision Support Using Simulation for Customer-driven Manufacturing System Design and Operational Planning”, in: Advances in Decision Support Systems, pp. 235-260, IntechOpen, 2010

[2] M. P. Roessler, J. Reimer, M. Mueller, "Decision Support for Choosing an Appropriate Simulation Method for Dynamic Material Flow Analysis", Journal of Industrial and Intelligent Information, Vol. 3, No. 4, pp. 337-341, 2015

[3] W. J. Hopp, M. L. Spearman, Factory Physics, Irwin McGraw-Hill, 2000

[4] M. Wilcox, M. Bourne, "Predicting Performance", Management Decision, Vol. 41, No. 8, pp. 806-816, 2003

[5] A. Neely, M. Gregory, K. Platts, "Performance measurement system design: A literature Review and Research Agenda", International Journal of Operations an Production Management, Vol. 25, pp. 1228-1263, 2005

[6] R. Sundkvist, Financial benefits of shoop floor productivity improvements, PhD Thesis, Chalmers University of Technology, 2014

[7] B. O. Odedairo, D. S. Ladokun, "Varying Lot -Sizing Models for Optimum Quantity- Determination in Material Requirement Planning System", Presented at the International Conference of Manufacturing Engineering and Engineering Management, London, UK, July 4-6, 2018

[8] S. Melnyk, D. Stewart, M. Swink, "Metrics and Performance Measurement in Operations Management: Dealing with the Metrics Maze", Journal of Operations Management, Vol. 22, pp. 209-217, 2014

[9] A. Gunasekaran, C. Patel, R. McGaughey, "A framework for supply chain performance measurement", International Journal of Production Economics, Vol. 87, No. 3, pp. 333-347, 2004

[10] D. Fasel, Fuzzy Data Warehousing for Performance MeasurementConcept and Implementation, Springer, Switzerland, 2014

[11] T. Taweesak, "Performance Measurement System Design and Implementation in Thai Automotive Industry", PhD Thesis, University of South Australia, 2005

[12] J. Lorentzon, Fredlund, Application of Performance Measurement on Manufacturing Simulations for Knowledge-Based Decision Support, MSc Thesis, Lund University, 2017

[13] P. Sandberg, M. Larsson, J. Dahl, M. Soderstrom, H. Vourinen, "In search of stability-Investigating Flexible and Stable Production Strategies for an Optimised Steel Plant", International Journal of Green Energy, Vol. 3, No. 2, pp. 159-170, 2006

[14] M. Gong, Using Exergy and Optimization Models to Improve Industrial Energy Systems Towards Sustainablity, PhD Thesis, Linkopings Universitet, 2004

[15] J. Persson, T. Berntsson, "Influence of Short-term Variations on EnergySaving Opportunities in a pulp Mill", Journal of Cleaner Production, Vol. 18, No. 9, pp. 935-943, 2010

[16] J. Jonsson, P. Ruohonen, G. Michel, T. Berntsson, "The potential for Steam Savings and Implementation of Different Biorefinery Concepts in Scandinavian Integrated TMP and Paper Mills", Applied Thermal Engineering, Vol. 31, No. 13, pp. 2107-2114, 2011

[17] S. Robinson, Successful Simulation: A Practical Approach to Simulation Projects, McGraw -Hill, 1994

[18] J. Banks, J. Carson, B. Nelson, D. Nicol, Discrete-Event System Simulation, Third Edition, Prentice-Hall, 2001

[19] N. Mardan, Combining Simulation and Optimization for Improved Decision Support and Energy Efficiency in Industry, Linkoping University Institute of Technology, Sweden, 2012

[20] M. Al Durgham, M Barghash, "A generalised framework for simulation -based decision support for manufacturing", Production Planning and Control, Vol. 19, No. 5, pp.518-534, 2008

[21] S. Kursun, F. Kalaoglu, "Simulation of Production Line Balancing in Apparel Manufacturing", Fibres in Eastern Europe. Vol. 12, No. 6, pp. 68-71, 2009

[22] B. Johansson, On Virtual Development of Manufacturing Systems: Proposal for a Modular Discrete Event Simulation Methodology, PhD Thesis, Chalmers University of Technology, 2006
[23] A. G. Hirschberg, K. G. Heitmann, "Simulation in German Industry -A survey", 9th European Simulation Symposium and Exhibition Simulation in Industry, Passau, Germany, pp. 429-433, October 19-22, 1997

[24] L. Holst, G. Bolmsjo, "Simulation Integration in Manufacturing System Development: A study of Japanese industry", Industrial Management and Data Systems, Vol. 101, No. 7, pp. 339-356, 2001

[25] J. Fowler, O. Rose, "Grand challenges in Modelling and Simulation of Complex Manufacturing Systems”, Simulation, Vol. 80, No. 9, pp. 469476, 2004

[26] B .O. Odedairo, D. Bell, "Framework for Introducing and Implementing Value Methods: A Novel Toolkit for Small and Medium Scale Industries in Developing Nations", International Journal of Basic and Applied Sciences, Vol. 9. No.10, pp. 87-95, 2009

[27] V. O. Oladokun, A. O Olaitan, "Development of a Materials Requirements Planning (MRP) Software", Pacific Journal of Science and Technology, Vol. 13, No. 1, pp. 351-357, 2012

[28] J. Spanier, "Thoughts about Essential of Mathematical Modelling", Mathematical Modelling, Vol. 1, pp. 99-108, 1980

[29] A. J. Jakeman, R. A Letcher, J. P. Norton, "Ten Iterative Steps in Development and Evaluation of Environmental Models", Environmental Modelling and Software, Vol. 2, No. 5, pp. 602-614, 2006

[30] W. Domschke, A. Drexel, Introduction to Operations Research, Springer-Verlag, 2007

[31] H. I. Yoon, W. Shen, "Simulation -based Real -Time Decision Making for Manufacturing Automation Systems: A review", Manufacturing Technology and Management, Vol. 8, pp. 188-202, 2006

[32] B. Kadar, A. Pfeiffer, L Monostori, "Discrete Event Simulation for Supporting Production and Scheduling Decisions in Digital Factories", 37th CIRP International Seminar on Manufacturing Systems, Digital Enterprise, Production Networks, Budapest, Hungary, pp. 444-448, 2004

[33] J. Heilala, J. Montonen, A. Salmela, P. Jarvenpaa, "Modelling and Simulation for Customer Driven Manufacturing System Design and Operations Planning”, IEEE 2007 Winter Simulation Conference, Miami, USA, December 7-10, 2007

[34] W. J. Hopp, M. L. Spearman, Factory Physics: Foundations of Manufacturing Management, Waveland Press, 2008

[35] G. L. Curry, R. M Feldman, Manufacturing System Modeling and Analysis, Springer, 2007 